\title{
La radio comercial en Colombia. El nuevo panorama digital de la comunicación y del periodismo*
}

\author{
Commercial Radio in Colombia. The New Digital Panorama of Communication and Journalism \\ A rádio comercial na Colômbia. O novo panorama digital da comunicação e do jornalismo
}

William Ricardo Zambrano ${ }^{\text {a }}$

Universidad Sergio Arboleda, Colombia

DOI: https://doi.org/10.11144/Javeriana.syp37-72.rccn

williamzambrano@usa.edu.co

ORCID: http://orcid.org/0000-0002-2804-9709

Redalyc: http://www.redalyc.org/articulo.oa?id=86057225008

Fecha de recepción: 05 Junio 2018

Fecha de aprobación: 23 Julio 2018

\section{Resumen:}

Las emisoras tradicionales hallaron en Internet un canal donde coexisten nuevos formatos, contenidos, narrativas y lenguajes para llegar a diferentes públicos, al tiempo que abren otras alternativas de procesamiento, elaboración y difusión de la información. Estos medios dominantes están en un afán por migrar sus contenidos a la red, ya sea para ofrecer un servicio complementario o para crear una simbiosis de convergencia mediática, en la cual se generen nuevos modelos de comunicación y de actuación del comunicador y del periodista. Para comprender estos nuevos paradigmas mediáticos, se analizó la transformación de la radio comercial análoga a digital a partir de las categorías: empresarial, tecnológica, informativa, diseño web, audiencias y tendencias profesionales y laborales. Para este propósito, se realizó una investigación teórica y aplicada de carácter documental, descriptivo y correlacional de cinco emisoras comerciales de seis cadenas radiales que existen en Colombia, con mayor audiencia y cobertura informativa a nivel nacional. Se identificó que, en la transformación de estas emisoras, se presentan nuevos escenarios para migrar e instalarse en canales digitales, los cuales están creando otro ecosistema de la comunicación más horizontal entre medios y audiencias que implica hacer cambios en el panorama mediático, en los formatos de recepción y en el desarrollo de nuevas mediaciones entre usuarios y contenidos de acuerdo a cada plataforma mediática.

Palabras clave: convergencia, audiencia, información, radio, diseño web.

\section{Abstract:}

Traditional radio stations have found in the Internet a channel where new formats, contents, narratives and languages exist together enabling to reach different publics and, in turn, to open other alternatives for processing, preparing and broadcasting the information. These mainstream media outlets are eager to migrate their contents to the web, either to provide a supplementary service or to create a media convergence symbiosis whereby new models will be created for both the communication and the communicator/journalist's performance. To understand these new media paradigms, this work analyzed the transformation from analogue to digital radio based on the following categories: business, technology, information, web design, and professional/labor audiences and trends. To that end, a theoretical and applied research was conducted in the form of a documentary, descriptive and correlational work including five commercial radio stations out of the six national radio companies in Colombia with greater audiences and information coverage. In the radio station transformation, it was identified that there are new scenarios to migrate and set up digital channels, which is bringing about a new ecosystem for a more horizontal communication between audiences and media. All this implies to carry out changes in the media panorama, in the delivery formats and in the development of new mediations between users and contents according to each media outlet platform.

Keywords: convergence, audience, information, radio, web design.

\section{Resumo:}

As estações de rádio tradicionais acharam na Internet um canal onde coexistem novos formatos, conteúdos, narrativas e linguagens atingindo a diferentes públicos, enquanto abrem outras alternativas de processamento, elaboração e difusão da informação. Estes meios de comunicação dominante estão num afã por migrar seus conteúdos para a rede, já para oferecer um serviço complementar já para criar uma simbiose de convergência mediática, onde se gerarem novos modelos de comunicação e atuação do comunicador e do periodista. Para compreender estes novos paradigmas mediáticos foi analisada a transformação da rádio comercial análoga para digital a partir das categorias empresarial, tecnológica, informativa, design web, audiências e tendências profissionais e

Notas de autor:

\footnotetext{
${ }^{a}$ Autor de correspondencia. Correo electrónico: williamzambrano@usa.edu.co
} 
laborais. Para este propósito, realizou-se uma pesquisa teórica e aplicada de carácter documental, descritivo e correlacional de cinco emissoras comerciais de seis cadeias radiais existentes na Colômbia, com maior audiência e cobertura informativa no nível nacional. Identificou-se que, na transformação destas emissoras, apresentam-se novos cenários para migrar e se instalar em canais digitais, os quais estão criando outro ecossistema da comunicação mais horizontal entre mídia e audiências envolvendo mudanças no panorama mediático, nos formatos de recepção e no desenvolvimento de novas mediações entre usuários e conteúdos de acordo a cada plataforma mediática.

Palavras-chave: convergência, audiência, informação, rádio, design web.

\section{Introducción}

\section{Uno, dos, tres... AL AIRE}

En medio de los frenéticos cambios generados por los avances tecnológicos, la radio sigue siendo una vieja, pero aún novedosa compañía de penetración en la sociedad; significa reconquistar el espacio del diálogo y se constituye en una práctica comunicativa que ofrece diversas propuestas como lo son la información, ensoñación y entretenimiento.

Según Arnheim (2015),

la radio estimula la unificación de la cultura popular, centraliza, colectiviza y estandariza; su misión es la de ilustrar deleitando; es la de hacer conocer al oyente lo que no puede leer en los libros o en los periódicos porque el tiempo no se lo permite (p.141).

Es una forma de construir sociedad, identidad y opinión; es por ello, que aprovecha sus dos mayores recursos: el lenguaje auditivo y la capacidad de generar estímulos en la parte imaginativa del escucha mediante la voz, silencios y efectos.

Delgado y Rioboo (2005) señala que "este medio permite crear un ámbito de juego, un espacio ideal para imaginar fantasías con la ayuda de la palabra, la música y los sonidos” (p. 102), por eso al ser tan versátil, resulta ser muy útil por las formas de narrar y contar las noticias a través de la voz de un periodista que hace que su historia tenga capacidad sonora de dibujar escenas que recreen la mente del receptor. La radio informativa no solo se basa en difundir este tipo de noticias, sino también se preocupa por fomentar la creatividad y la participación del ciudadano.

Este medio tradicional es parte de la vida de Colombia, ha sido el que ha acompañado al país en los buenos y malos momentos desde el comienzo del siglo XX, juega un papel decisivo en la construcción de nación: une las voces regionales, permite que Colombia se escuche a sí misma y se reconozca en sus diferencias, "difunde las diversas culturas, transmite los acontecimientos políticos, divulga los movimientos sociales y crea diálogos nacionales acerca de los principales problemas y adelantos del país" (Documento de política sectorial del Ministerio de Comunicaciones, 2004).

La radio en Colombia ha tenido un gran impacto y un altísimo consumo, cuenta con un índice de sintonía de 240 minutos diarios en promedio por persona que equivale a cuatro horas, seguida por la televisión con 180 minutos e Internet con 120 minutos de consumo diarios (ACIM, 2017). Según Min TIC (2017) es el medio con más alcance y difusión del país, 48,3 millones de colombianos, que corresponden al 99,1\% de la población nacional escuchan radio. Es masivo y el de mayor alcance, llega a toda la sociedad de forma más directa, personal y persuasiva, la voz facilita que la imaginación recree escenarios, personajes y hechos; es decir, es multicultural y multigeneracional, registra y cuenta acontecimientos en directo a través de géneros periodísticos como noticia, entrevista, reportaje y crónica. 


\section{El ocaso de la radio en A.M y F.M. y el renacer de la radio en internet}

Esta radio en sus 89 años de existencia en nuestro país, ha vivido cuatro revoluciones, la primera, a mediados del siglo XX, con la invención de los transistores que permitió sacarla del hogar a través del portátil; la segunda, cuando los radios de frecuencia modulada aparecieron para mejorar la calidad del sonido, creación de emisoras de corto y mediano alcance, propuestas de programación temática y la segmentación de púbicos; la tercera, producto de la tecnología digital, la cual renovó la producción analógica; y la cuarta revolución, se centró en la radio en las plataformas de Internet ${ }^{1}$.

En atención a estas revoluciones, se toma las siguientes definiciones de la radio tradicional, de internet y digital. La radio convencional es aquella que utiliza el espectro electromagnético en las bandas de amplitud modulada (AM) y frecuencia modulada (FM), mediante señales análogas para difundir cualquier programación con cobertura nacional, regional o local. La de Internet es toda emisora que transmite señales binarias convertidas en análogas que para su difusión utiliza plataformas digitales como telefonía móvil, redes fijas o inalámbricas, espectro radioeléctrico, streaming o podcast.

Estas radios en la web no necesitan de antenas, bandas de transmisión AM o FM, ni de sistemas de onda corta, sino de un computador o un dispositivo móvil: celular o tableta, lo que obliga a un contenido breve con hipervínculos, de modo que los usuarios puedan obtener más información complementada con imágenes, gráficos y otros datos, que resulten instrumentos novedosos lo cual la hace más personal e interactiva, ampliando la oferta de contenidos especializados, los canales para su distribución y la gestión del sonido a través del ordenador.

Según Romero (2013) "la radio digital es producto de la convergencia multimedia, donde el sonido, único elemento de la radio de antena, se ve acompañado por elementos visuales” (p.37). Durante la última década parecía que la radio digital debía tener un solo nombre sin tener claro cuál: DAB (Digital Audio Broadcasting) o DRM (Digital Radio Mondiale) o IBOC (In-Band On-Channel) o ISDB (Integrated Services Digital Broadcasting), etc. olvidando que ya existe una radio digital sin siglas, la de Internet (Lavers, 2017), y que una cosa son los estándares tecnológicos y otra, las plataformas de distribución de los contenidos radiofónicos o de audio en general.

Valencia (2008) dice que "la radio digital posee audio de excelente calidad junto con textos e imágenes que se pueden ver en pantallas en los receptores, con lo cual expande el medio radial para incluir contenidos multimedia” (p. 115) La apuesta por la digitalización no es de ahora, lo cual lo recuerdan Peñafiel y López (2002): "Se comenzó a plantear hace algunos años, con los ojos puestos en la transición al tercer milenio, teniendo en cuenta las ventajas que ofrecía la convergencia de medios y soportes que ofrecen las tecnologías" (p. 96).

\section{La radio sin radio: la era de los dispositivos móviles}

En 2013, la programación informativa de AM migró a la banda FM y a la red para ser escuchada en dispositivos móviles. El reto fue crear contenidos instantáneos con audio, texto, fotos, video e infografías. Desde ese momento estos medios dominantes se vieron obligados a organizar el proceso de transferencia de información desde el canal de broadcasting a la pantalla interactiva. Las cadenas propusieron versiones para Internet, innovación para su página web y mayor importancia al sitio que se encargaba de coordinar y gestionar contenidos y de mantenerlos actualizados. Se integró a los periodistas para presentar la información escrita, sonora, fotográfica y audiovisual en sus diferentes medios del mismo grupo económico.

La radio comercial en 2014 se destacó por su cubrimiento gracias al 4G, App Store, Windows phone, Android Market, tabletas, portátiles y redes de Internet. Además las aplicaciones como Whats App que facilitó la interacción mediante texto, fotos y gráficos. Las voces se grababan en medios digitales y los directos se 
hacían desde cualquier parte gracias al celular o al teléfono satelital. Se dio mayor importancia a la interacción con sus oyentes a través de redes sociales, correos electrónicos y mensajes de texto. Se le sumó los marcadores en línea y las estadísticas en tiempo real de consulta de la audiencia de la página y de cada programa radial en la red.

Dos años después, la preocupación de los gerentes y directores de las cadenas y emisoras fue crear estrategias para aumentar la sintonía; es decir, el consumidor era parte de la producción informativa: había que producir para lo análogo y digital, integrar equipos para transferir contenidos de un medio tradicional a la web, contar con redactores en línea para generar sus propias noticias. Era necesario conformar un grupo interdisciplinario de periodistas, fotógrafos, infógrafos y programadores.

\section{La radio comercial en Colombia}

Estos conglomerados mediáticos tienen como objetivos la rentabilidad, anunciar sus productos y ser dueños de varios medios. Es una industria seria, estructurada, muy importante e influyente, quizás la de mayor porcentaje de participación en la "torta publicitaria", por lo cual ha desarrollado tres estrategias para mantener los niveles de penetración y consumo: 1) Los teléfonos celulares que le ofrecen al usuario sintonizar frecuencias en la banda FM del espectro convirtiéndose en 'radiorreceptores'. 2) La posibilidad de escuchar las emisoras vía streaming a través de computadores y dispositivos móviles (cada que se vende un celular, en la mayoría de los casos se está vendiendo un radiorreceptor). 3) El aumento del tiempo de desplazamiento en vehículo en las ciudades grandes, donde la radio sigue siendo la reina.

Una de las ventajas que tiene la radio, es la segmentación de audiencias, esto significa que las emisoras y las cadenas por su formato, se diferencian en el tipo y la composición de sus oyentes por edades, sexos y nivel socioeconómico, donde para la radio informativa el $81 \%$ de su oyentes pertenece a estratos medios y altos, mayores de 35 años (ECAR, 2017a); por eso estas estaciones buscan cada vez mejorar la fidelidad de sus consumidores y aumentar sus índices de sintonía y rentabilidad; son de carácter privado, cuya programación está destinada a la satisfacción de los hábitos y gustos del oyente.

Cumplen una función netamente comercial, por ende, son con ánimo de lucro, sus ingresos provienen fundamentalmente de la venta de pauta publicitaria, arrendamiento de espacios, entre otros. Según la Subdirección de Radiodifusión Sonora (Min TIC, 2017) hoy en día hay 1596 emisoras que transmiten su señal por medio del espectro radioeléctrico, 626 son comerciales en A.M. y en F.M., unas independientes y otras pertenecientes a las seis cadenas radiales: Caracol, RCN, Melodía, Todelar, Súper y Colmundo Radio, las cuales transmiten música, entretenimiento, programas culturales, deportes y noticias.

Las cinco emisoras más escuchadas son de tres conglomerados mediáticos: Grupo Prisa: Caracol Radio y La W. Radio. Grupo Santo Domingo: Blue Radio. Organización Ardila Lülle: RCN Radio y La F.m. Esta clasificación es producto del promedio de los resultados suministrados por las dos empresas de medición de audiencias en Colombia: Estudio Continuo de Audiencia Radial (2017b) y Estudio General de Medios (2017) que identificaron entre marzo a junio de 2017, el consumo de radio en las edades de 12 a 69 años en 18 ciudades de Colombia.

Estos monopolios, comprendieron que la radio comercial debía replantearse, concentrarse en ofrecer innovación de sus contenidos, formatos, narrativas, lenguajes y audiencias; entendieron que para competir tenían que comenzar con la transformación de lo análogo a lo digital y de todo su ecosistema comunicativo, tecnológico, producción informativa y en sus rutinas periodísticas.

Por estas razones, se investiga la transformación de la radio comercial análoga a digital de cinco emisoras con mayor audiencia y cobertura informativa a nivel nacional que están viviendo la convergencia: Caracol Radio, La W. Radio, Blue Radio, RCN Radio y La F.m, las cuales están sumando y migrando sus contenidos a la red, ya sea para ofrecer un servicio complementario o para crear una simbiosis mediática. 
Para tal fin, se analizaron las siguientes categorías con sus respectivas variables: Empresarial: grupos multimedia y negocio. Tecnológica: canales, soporte y convergencia. Informativa: formatos y enfoques. Periodística: contenidos, géneros periodísticos, gestión de la información, lenguajes, narrativas, escritura y producción. Diseño web: multiplaformas, color, arquitectura de navegación, diagramación e interacción. Audiencias: recepción, redes y comunidades. Profesional y laborales: rutinas de trabajo, habilidades y conocimientos del comunicador y periodista.

\section{Metodología}

Se realizó una investigación teórica y aplicada, cualitativa y cuantitativa de carácter documental, evaluativo, crítico y prospectivo a partir de un análisis descriptivo y correlacional de las emisoras mencionadas que pertenecen a tres cadenas de las seis que existen en Colombia. La investigación se realizó del 7 enero al 30 de mayo de 2018 en Bogotá, Medellín, Cali, Barranquilla, Cartagena, Santa Marta, Cúcuta, Ibagué, Bucaramanga, Villavicencio, Pereira, Manizales, Pasto, Montería y Neiva, ciudades de mayor índice de audiencia radial.

Para la selección de los individuos a encuestar y entrevistar en forma personal, se utilizó una metodología de muestreo probabilístico, en la que todos los elementos de la población tuvieron la misma posibilidad de elegirse, lo que conllevó a que la selección se hiciera aleatoria: 6 directores de emisoras, 22 periodistas de radios tradicionales, 25 de radios digitales que operan en Internet, 18 editores generales, 15 jefes de redacción, 16 decanos, 12 directores de programas de Comunicación y Periodismo, 32 oyentes de emisoras de AM y FM y 33 usuarios de las páginas web de las radios objeto de estudio.

Para el análisis de las emisoras análogas, se hicieron entrevistas en profundidad y encuestas mediante un cuestionario personalizado con las categorías y variables de la investigación; posteriormente, se realizó una prueba piloto que permitió hacer los ajustes pertinentes y validar el instrumento. Tres encuestados no respondieron, lo cual no influyó en los resultados.

Para la selección de la muestra, se tuvo en cuenta la franja más escuchada, la cual es la noticiosa en el horario de 6:00 a.m. a 10:00 a.m. con 27'928.400 oyentes y cobertura nacional de 79,1\% (ECAR, 2017b; EGM, 2017). Las emisoras más sintonizadas con sus respectivos noticieros y porcentajes de audiencias, son las siguientes: La W Radio (29\%), Caracol Radio (21\%), Blu Radio (19\%), RCN Radio (12\%) y La F.m. (6\%). Por bloques, el horario de la mañana es el de mayor importancia para los adultos, los jóvenes prefieren la media mañana y la tarde. El lunes es el día de mayor audiencia para los estratos altos, el martes y jueves para los bajos, y el domingo para los medios. Los hombres son los que más escuchan radio.

Para la migración, selección y análisis de las páginas en red de estas estaciones de radiodifusión, se tuvieron en cuenta las siguientes razones: a) caracol.com.co, es el sitio de noticias con mayor tráfico en el país; b) wradio.com.co, es la segunda página más consultada, además de ser la más innovadora en materia de contenidos digitales; c) bluradio.com y rcnradio.com, combinan lo análogo y lo digital, se destaca su información en soporte web, además de ser las dos emisoras en tercer lugar más consultadas en sus respectivas plataformas tecnológicas. Y La Fm.com.co, es el sitio digital donde se refleja una mezcla entre periodismo clásico y moderno.

Se estudiaron las cinco emisoras referenciadas con sus respectivas URL activas durante cuatro semanas, de lunes a viernes para una muestra de 20 días; igualmente, se hicieron impresiones de pantalla de la página de inicio por hora de cada uno de los medios desde las 6:00 a.m. a las 12:00 m. En promedio se obtuvieron diez capturas diarias de la página tecnológica de cada emisora para un total de 200 para su análisis. Para la ponderación de cada categoría y variable se asignó una importancia del $100 \%$, que reflejó los porcentajes de la investigación. Los resultados se ordenaron a partir de la información obtenida, además de la revisión 
pormenorizada de la programación informativa de los noticieros de cada radio ( 97 horas de grabación y 127 podcasts) y análisis de contenido digital de 40 publicaciones por emisora en su respectiva página web.

Mediante una tabla en Excel, se sistematizó la información sobre la pre, pro y pos producción de la información periodística derivada de la especificidad del soporte análogo y digital, lo cual permitió construir las matrices de cada categoría para identificar los cambios noticiosos durante el día de cada emisora a fin de realizar un análisis comparativo del consumo por parte de la audiencia (escucha-lector) en la jerarquización de la información y de las secciones más relevantes en el primer scroll del sitio.

Se complementó dicha información con la investigación etnográfica, la cual optimizó la validez de la interpretación de las encuestas y entrevistas. Además, permitió identificar las dinámicas convergentes y divergentes de estos medios. Posteriormente, se integraron y correlacionaron los resultados de cada instrumento aplicado y se triangularon las categorías y variables correspondientes que dieron cuenta del carácter evaluativo y crítico de la transformación de estas estaciones radiales.

La investigación se divide en tres partes: la primera, presenta los estudios sobre la transformación de la radio, la segunda, articula los resultados, el análisis y la discusión sobre el objeto de estudio y la tercera parte, presenta las conclusiones.

\section{Estudios sobre la transformación de la radio}

Las investigaciones sobre radio análoga han sido muy escasas, generalmente basadas en autores como Mata (1993) y Alfaro (1993), quienes ven a la radio como medio articulador entre el poder, las condiciones de vida y la cultura de los actores de la sociedad civil. Kaplún (1994) y Balsebre (2004), se han centrado en las debilidades del medio, la unisensorialidad, recepción, capacidad de cobertura limitada y distracción de la audiencia realizando otras tareas.

Forgacs (2001), Idei (2002), Gordon (2003), Jenkins (2004); Klinenberg (2005), Killebrew (2005) y Lawson-Borders (2006) han investigado la convergencia como un fenómeno sistémico. Theodoropoulou (2003), Duhe et al. (2004) y García Avilés y Carvajal (2008) han estudiado las logísticas de integración de redacciones.

Montse (2011) analiza la situación de la radio digital en un momento en que la audiencia está saturada de ofertas y quiere productos que respondan a la movilidad de los aparatos con que cuentan los usuarios. Pese a que nos encontramos en un mundo digitalizado y se embarca en el uso y consumo de artefactos tecnológicos, aun se continua con un pensamiento y forma de actuar analógica, de ahí que se deba asumir y culturizar tecnológicamente para asumir los cambios impredecibles que están por venir.

Salaverría y García (2008) analizaron la convergencia en los medios de comunicación y los retos que implica para el periodista pasar de trabajar en un formato con un lenguaje y una rutina, a fusionar todo en uno. Con el auge de las nuevas tecnologías, las empresas informativas se transforman en grupos multimedia en las que integran las salas de redacción y producción, lo cual implica un cambio de mentalidad y por ende, de rutina de trabajo para el profesional de la comunicación. Se presentan fusión de roles: ciertas actividades que en el pasado correspondían a dos o más profesionales, ahora son ejecutadas por uno solo.

Los estudios sobre radio digital analizan las eventuales transformaciones que la tecnología y sus condiciones de diseño y adopción producen en el modelo existente de comunicación radial, en particular las formas en que su adopción está alterando los balances de poder previos entre los productores públicos y privados. Según Valencia (2008) en el Reino Unido, "los intereses de los operadores radiales privados y de la BBC, la gran cadena pública, han convertido a la radio digital en un nuevo campo de batalla”. (p. 111)

Bonet (2017) en su investigación presenta la situación de la radio digital, que consiste en cuáles son los principales estándares y a través de qué plataformas puede servirse a una audiencia cada vez más exigente, móvil y saturada de ofertas mediáticas de todo tipo. Aunque, se habla de diferentes sistemas de distribución 
de audio digital, se centra en los principales estándares de difusión, vía hertziana. Concluye que se empezó la digitalización con una mentalidad analógica, esto es el desarrollo de un modelo para cada medio cuando cada vez parece más claro que el futuro apunta hacia una concepción de estándares multimediales adaptados a una recepción multiplataforma.

De otra parte, Martínez y Herrera (2004) en su investigación, sientan las bases para la elaboración de una teoría de los géneros radiofónicos recuperando los principales aportes teóricos realizados hasta la fecha en España. A partir de la descripción y valoración del corpus teórico, se proponen pautas y variables para elaborar una nueva teoría de los géneros radiofónicos.

Sierra (2010) estudia la programación, contenidos y adaptación de nuevas tecnologías en la radio autonómica española; concluye que la base programática está concentrada en tres propuestas: información, entretenimiento y deportes. Gutiérrez (2013) investiga las estrategias de programación de las radios generalistas en España, afirman que esta oferta tiende a una homogenización de estrategias y en la que convergen propuestas similares en los mismos horarios de modo que el oyente se decide por consumir contenidos con una u otra oferta, pues son pocos los que se atreven a innovar y ofrecer algo diferente.

Un estudio similar lo hacen Gutiérrez, Ribes y Monclús (2012) sobre los hábitos de consumo mediático generados por Internet e identifican qué tanto los jóvenes recurren al medio tradicional para informarse y entretenerse. Al tratarse de un estudio en desarrollo no se dejan conclusiones, sino que se esbozan resultados preliminares del consumo mediático por parte de los jóvenes y ratifican que no se puede partir de presunciones, sino que en tecnología es necesario ratificar los imaginarios.

Dominique (2010) en "Informar no es comunicar", plantea las diferencias entre informar y comunicar, teniendo como idea central analizar mediante su propia teoría de la comunicación, cómo el aumento de información ha generado más desinformación en la sociedad por los avances de la tecnología. A su vez, Gutiérrez (2013) en "La Calidad informativa en la era digital: el gran reto" (p. 666), evalúa como la información influye en las personas. Las tecnologías pasan por procesos que involucran la calidad periodística y dependiendo del uso que se les dé, determinar si la información es buena o mala.

En síntesis, estas investigaciones evidencian que la radio se está reinventando y buscando el camino cómo integrarse al entorno multimedia que le puede proporcionar a la audiencia espacios de navegación en los cuales se encuentran elementos visuales y sonoros al tiempo que se redefinen los intereses informativos del usuario y del medio. Se concluye que son pocas las investigaciones y estudios que se han realizado sobre la transformación de la radio análoga a digital, los cuales empiezan a ser el cimiento de futuras investigaciones, abriendo así un campo poco desarrollado; sin embargo, queda todavía un largo camino por recorrer y profundizar sobre la radio comercial en Colombia como nuevo paisaje digital de la comunicación y del periodismo.

\section{Resultados}

\section{Nuevas formas y modelo de negocio radial}

La estrategia comercial de estas cinco organizaciones, se fundamenta en obtener beneficio económico a través de la presentación de contenidos actuales y de interés para determinadas audiencias. Así mismo, establecen una segmentación de los oyentes en términos de edad, género, gustos, consumos culturales y franjas en las que se escucha radio, de esta forma, los anunciantes saben en qué momento del día deben comprar los espacios de publicidad para tener la mayor cantidad de oyentes posibles.

El modelo de radiodifusión comercial, considera a sus audiencias como consumidores dispuestos a escuchar información y adquirir productos, su fin es ubicar el mayor número de radios de su propiedad o afiliadas en las diferentes ciudades. Este esquema de negocio utiliza el dial o frecuencia enmarcado en el espacio 
electromagnético (AM-FM) no para educar ni culturizar sino para entretener, lo que le permite cubrir las zonas nacionales; del mismo modo, está regido por las leyes del mercado: el raiting del ECAR (2017a) y del EGM (2017), cuyos resultados inciden en la rentabilidad basada en la pauta publicitaria.

La W Radio es la emisora con mayor publicidad privada (50)\%, mientras que Caracol es líder en Publicidad oficial y Blue Radio es primera en publicidad del mismo grupo económico con un 35\%. RCN es primera en eventos especiales con un 11\% y la F.m lidera en venta de servicios con el 3\%.

TABLA 1

Fuentes de financiación

\begin{tabular}{|l|c|c|c|c|c|}
\hline \multicolumn{1}{|c|}{ Financiación } & $\begin{array}{c}\text { La W } \\
\text { Radio }\end{array}$ & $\begin{array}{c}\text { Caracol } \\
\text { Radio }\end{array}$ & $\begin{array}{c}\text { Blu } \\
\text { Radio }\end{array}$ & $\begin{array}{c}\text { RCN } \\
\text { Radio }\end{array}$ & $\begin{array}{c}\text { La } \\
\text { F.m. }\end{array}$ \\
\hline Publicidad privada & $50 \%$ & $42 \%$ & $40 \%$ & $44 \%$ & $43 \%$ \\
\hline Publicidad oficial & $13 \%$ & $14 \%$ & $10 \%$ & $11 \%$ & $9 \%$ \\
\hline Publicidad del mismo grupo económico & $25 \%$ & $32 \%$ & $35 \%$ & $27 \%$ & $29 \%$ \\
\hline Publireportajes & $2 \%$ & $1 \%$ & $3 \%$ & $2 \%$ & $4 \%$ \\
\hline Venta de servicios (concesiones horarias) & $1 \%$ & $0 \%$ & $1 \%$ & $2 \%$ & $3 \%$ \\
\hline Eventos especiales & $8 \%$ & $10 \%$ & $9 \%$ & $11 \%$ & $9 \%$ \\
\hline Otros & $1 \%$ & $1 \%$ & $2 \%$ & $3 \%$ & $3 \%$ \\
\hline
\end{tabular}

Fuente: los medios objeto de estudio (elaboración propia)

También estas emisoras, le apuntan a los modelos de negocio emergentes ante el impulso de los contenidos digitales a partir de los Big Data, para identificar los patrones de consumo, personalizar la publicidad y la oferta de productos y servicios catalogados como impulsores que pueden incidir en la reducción de precios por cuña, en la facturación o la ampliación de las cadenas de valor según la programación, franjas, número de internautas y dispositivos conectados a Internet.

\section{La tecnología: la estética del campo informativo}

Cada emisora justifica la creación de su plataforma en Internet, unas estáticas y otras móviles para visibilizar sus contenidos análogos a través de una red más cohesionada, con tres objetivos específicos: primero, hacer más fácil localizar, compartir e integrar información; segundo, propiciar el periodismo participativo mediante una red social o web 2.0 donde las audiencias desarrollen comunidades interactivas colaborativas de información; y tercero, que la página motive la venta de publicidad.

Las cinco emisoras en sus páginas digitales presentan información relevante en temas de política, deporte, entretenimiento y economía; incluyen el código HTML que permite interpretar la información al acceder a la web. Así mismo, mantienen una estructura jerarquizada de etiquetas mediante un lenguaje RSS, que proporciona a los usuarios el contenido a través de la página, con el título y fecha de publicación del podcast. Dentro de estas páginas radiales, en sus contenidos no aparecen el nombre del autor ni tampoco audios en idiomas diferentes al español.

\section{Diseño y navegación}

Las cinco emisoras presentan un diseño visual estándar en sus elementos de interface para ser consultados en computadoras, smartphones o tabletas. Sus páginas resaltan las noticias nacionales e internacionales con algunos recuadros, frases destacadas, videos y galerías que contiene la información relevante que inicialmente fue emitida en formato análogo. 
La arquitectura de la página digital de cada medio es el siguiente: su esquema de navegación está basado en una estructura por niveles: el Home (Inicio) del cual se desprenden las categorías que llevan a un despliegue a los contenidos específicos: programas, ciudades de cubrimiento, noticias locales, nacionales e internacionales, deportes, podcasts, especiales, entretenimiento y blogs; ninguna tiene descripción ni migración a prosumidores. Estos sitios usan colores, imágenes y letra estándar; su entorno digital de la página web está distribuido así: fotos $10 \%$, animaciones $1 \%$, infografías $2 \%$, videos $17 \%$, recuadros $8 \%$, audios $58 \%$ y textos $34 \%$.

La proliferación de productos y servicios informativos digitales están soportados en estructuras conformadas por las variables expuestas con sus respectivos porcentajes, lo cual la combinación de las técnicas clásicas de gestión de información —audio- con las características propias del medio digital — recuadros, videos, infografías, animación, textos, fotos y galerías - se unen; es decir, que se está configurando un esquema circular de $360^{\circ}$ en el tratamiento de la información que se presenta en el sitio análogo y digital, tan solo difiere en el entorno tecnológico en la integración del contenido como se relaciona en la siguiente tabla.

TABLA 2

Estructura por niveles

\begin{tabular}{|l|c|c|c|c|c|}
\hline \multicolumn{1}{|c|}{ Categorías } & $\begin{array}{l}\text { La W } \\
\text { Radio }\end{array}$ & $\begin{array}{l}\text { Caracol } \\
\text { Radio }\end{array}$ & $\begin{array}{l}\text { Blu } \\
\text { Radio }\end{array}$ & $\begin{array}{l}\text { RCN } \\
\text { Radio }\end{array}$ & $\begin{array}{l}\text { La } \\
\text { F.m. }\end{array}$ \\
\hline Noticias locales & $12 \%$ & $16 \%$ & $14 \%$ & $13 \%$ & $14 \%$ \\
\hline Noticias nacionales & $52 \%$ & $72 \%$ & $64 \%$ & $71 \%$ & $62 \%$ \\
\hline Noticias intemacionales & $36 \%$ & $12 \%$ & $22 \%$ & $15 \%$ & $24 \%$ \\
\hline Deportes & $25 \%$ & $27 \%$ & $19 \%$ & $22 \%$ & $19 \%$ \\
\hline Especiales & $3 \%$ & $2 \%$ & $2 \%$ & $1 \%$ & $1 \%$ \\
\hline Entretenimiento & $7 \%$ & $8 \%$ & $5 \%$ & $6 \%$ & $5 \%$ \\
\hline Podcast & $23 \%$ & $25 \%$ & $12 \%$ & $10 \%$ & $9 \%$ \\
\hline Blogs propios & $4 \%$ & $5 \%$ & $3 \%$ & $2 \%$ & $2 \%$ \\
\hline Blogs de los usuarios & $2 \%$ & $2 \%$ & $1 \%$ & $1 \%$ & $1 \%$ \\
\hline
\end{tabular}

Fuente: esta investigación (elaboración propia)

Caracol en noticias locales y nacionales es líder con el $16 \%$ y $72 \%$, respectivamente. En noticias internacionales la W Radio es primera con 36\%. En realización de podcast Caracol aventaja a la W en un 2\%. La emisora que más publica blogs propios es Caracol.

Caracol Radio tiene un diseño minimalista y sobrio, con una combinación de colores negro, rojo y blanco. Su plataforma presenta noticias acompañadas de imágenes que hacen la lectura y consulta de audios más entretenida e interactiva. La W Radio, enfatiza en el amarillo fuerte quemado con rojo en degradé blanco. Blu Radio, tiene un diseño estético y minimalista, priman el azul y el blanco; contiene información de actualidad nacional e internacional.

La información en las páginas en línea de RCN Radio y La F.m, hacen uso de los mismos colores de la Organización Ardila Lule: azul y verde; sus noticias son fáciles de localizar, los casos de interés, se resaltan con negrilla. Ninguna tiene un mini tutorial o tour donde, de manera sencilla, se manejen las funcionalidades principales del sitio. Estas páginas digitales son consultadas por el 46\% de usuarios de 8:00 p.m. a 10:00 p.m., 15\% de 4:00 p.m. a 6:00 p.m., 14\% después de la 1:00 p.m. 3\% de 6:00 a.m. a 8:00 a.m. El dispositivo que más utiliza la audiencia es el celular con el $87 \%$ y el computador el $9 \%$. El promedio de visitas por sitio web es: Caracol Radio 6.500, La W Radio 5.820, Blu Radio 3.025, La F.m. 3.009 y RCN Radio 2.920.

Los sitios digitales de Caracol (s.f.) y W Radio (s.f.) son los de mayor tráfico en Internet, aparecen entre los primeros resultados que arrojan las principales herramientas de búsqueda; el usuario sin necesidad de hacer exploraciones especiales los encuentra, entiende el funcionamiento y navega amigablemente en las respectivas 
plataformas. Se destaca la página Blu Radio (s.f.), por la combinación de palabras clave dentro del título y por su recordación por parte de los usuarios que vuelven a la página luego de tener días sin consultarla. Las páginas La F.m (s.f.) y RCN Radio (s.f.), son fáciles de consultar y localizar por medio de metadatos, etiquetas y temas.

La diagramación y ubicación de los elementos en el entorno digital (Lay-outs) de la primera pantalla de la página de cada medio de comunicación, muestra la distribución de los contenidos, su localización y prioridad. Los sitios de RCN Radio y La F.m (s.f.), son operados colectivamente con una clara división de roles, entre contenido, diseño, tecnología y publicidad.

Dicha información presentada en RCN Radio y de La F.m, es replicada en cada página del respectivo medio. Se destaca sus transmisiones en vivo y en directo a través del AM, FM y su página en red, lo único que debe hacer el usuario es dirigirse a la parte superior de la misma y hacer clic donde dice "al aire", o en su defecto consultar las noticias o escuchar los podcasts de la información más importante del día, así mismo, mantienen actualizados a sus usuarios desde sus redes sociales que por lo general son Facebook y Twitter. La página de Blu Radio (s.f.), tiene una unidad de contenido integrada por gestores de información que la consiguen, la producen, la editan y la diseñan, con el ánimo que sea atractiva para el usuario, lo cual se refleja por el número de visitas diarias.

Estas cinco emisoras con sus respectivas páginas analizadas presentan la información mediante títulos, subtítulos, frases descriptivas y textos cortos en forma de sumario, claves para llamar la atención del usuario para motivarlo a permanecer en la página web, diferente en la emisión análoga. Así mismo, emplean todos los procesos involucrados en la agregación, transformación, agrupación, presentación y distribución de información según los propósitos trazados en cada una de las salas de redacción.

Los periodistas consultados expresaron que el método para el diseño y desarrollo de la información en el entorno web de cada medio, conlleva la inclusión de elementos digitales como textuales, gráficos y sonoros; es decir, se está aplicando un modelo estático a otro mucho más dinámico que permite la reutilización de los contenidos. Es así que la tarea de estos profesionales se ve modificada, debe gestionar la información para que llegue a los usuarios adecuados de forma pertinente y en el tiempo oportuno.

La W Radio y RCN Radio, se basan en indagaciones de amplia o fácil difusión que incluyen historia principal con sus respectivas sub historias soportadas en documentaciones, inmersiones en el contexto del acontecimiento y en diferentes puntos de vista. Caracol Radio y La F.m, presentan en sus páginas web seriales de las entrevistas; construyen las historias noticiosas con coherencia y continuidad editorial y con la colaboración de varios periodistas que además de comprender la noticia, la complementan con testimonios de fuentes que han vivido el hecho.

\section{Nuevas dialécticas de realización}

Caracol Radio realiza el cubrimiento informativo permanente; La W Radio, lo hace simultáneamente en corto tiempo; Blu Radio, busca que sus noticias sean de gran impacto; RCN Radio, que su cobertura noticiosa sea más detallada, clara e inequívoca; y La F.m. que su afinidad noticiosa con la audiencia sea permanente. Transmiten los acontecimientos con la ubicación de sus periodistas y equipos en determinados sitios para originar en directo de acuerdo con la capacidad tecnológica. Emplean la emisión en función del 'último minuto' o 'noticia en desarrollo', la cual la presentan en sus canales análogos con promedio de cinco a ocho minutos.

Caracol Radio y RCN Radio, presentan en sus informativos dos tipos de archivos: uno contiene podcasts de dos a tres minutos y otros de una hora de duración. La W Radio y La Fm, alojan en un servidor los contenidos noticiosos, determinado número de peticiones de descarga a la hora. La W Radio y Caracol Radio, reciben una media de 37 solicitudes por hora, mientras que Blu Radio, 22; RCN Radio, 16; y La Fm, 6. Las dos primeras emisoras actualizan la información cada 33 minutos, mientras que las restantes en promedio lo hacen cada hora. En general, $27 \%$ de los sitios se actualizan cinco veces al día, $17 \%$ dos veces y $4 \%$ una vez. 
Los contenidos emitidos en las diferentes emisoras de AM y FM son reproducidos en cada una de su plataforma web o a través de los dispositivos móviles. RCN Radio y La Fm, utilizan los podcasts como una extensión, remozada y amplificada de los audioblogs, mientras que Caracol Radio y Blu Radio, los emplean como una extensión sonora de algunas noticias cortas de un minuto a tres, las cuales son tituladas con el nombre del informativo, y no con el del periodista.

La visibilidad del estado del sistema de cada sitio radial mantiene informado al usuario de lo que está ocurriendo. Se destaca en Caracol Radio, RCN Radio y La F.m. un lenguaje con expresiones y palabras que le resultan familiares a su audiencia; La W Radio y Blue Radio, usan un lenguaje más elaborado con un orden lógico y natural de sus mensajes informativos, los cuales están muy definidos en sus páginas digitales.

Existen pocos blogs en estas páginas digitales, el grupo de periodistas consultados de estas emisoras, afirman no tener blogs propios, solo 13 tienen en forma independiente al medio de comunicación donde trabajan, hacen énfasis en noticias, información general, comentarios, reseñas y fotos. El $4 \%$ de sus periodistas albergan sus propios blogs y tienen cuentas en redes sociales, pero no son oficiales del medio para el cual trabajan, en ocasiones comparten la noticia a los usuarios a través de correo electrónico, Facebook, Twitter u otras formas de conexión social.

\section{Información expandida}

Caracol Radio sube algunos informativos de las emisoras a Youtube mientras que RCN Radio en Apps (aplicaciones en dispositivos móviles). Los reporteros de La W Radio emplean el celular para informar o realizar entrevistas, las cuales son enviadas por WhatsApp para ser emitida al aire. Blu Radio y La F.m., hacen un manejo complejo y a la vez cambiante de registro y envío de información a las diferentes pantallas de cada organización mediática a la que pertenecen.

La W Radio, Caracol Radio y Blu Radio tanto en AM y FM como en sus sitios web producen en promedios $42 \%$ información general, $16 \%$ de opinión, $17 \%$ de análisis y $16 \%$ de información especializada. RCN Radio y La F.m., presentan 31\% de información general, 38\% de opinión, 14\% de análisis y 12\% de información especializada.

Caracol Radio y RCN Radio utilizan sus páginas digitales para alojar el mismo contenido noticioso emitido tanto en A.M. como en F.M. La primera incorpora algunos componentes multimedia a su sitio digital y genera un modelo interactivo donde se evidencia que la fugacidad, la unisensorialidad y su límite territorial ya no son obstáculo. La segunda cadena redimensiona su información, tiempos y espacios, con elementos de Internet como navegación, hipertextualidad, hipermedialidad e interactividad. Blu Radio, utiliza el hipertexto que cataloga el contenido de su página, mientras que RCN Radio y La F.m., usan la indexación de palabras clave para identificar la página en la red.

Los flujos de información se incrementaron para los periodistas en sus respectivos sitios web a diferencia de las rutinas de trabajo empleadas en la producción para las emisoras análogas. La cobertura noticiosa, se realiza en tiempo real con muy pocos pregrabados, mientras que en las radios en línea se hace en promedio cada diez minutos. La W Radio y Caracol Radio transmiten en directo lo que está sucediendo; Blu Radio y RCN Radio mantienen ritmos de cobertura y rutinas de trabajo entre lo pregrabado y la inmediatez. La F.m. gestiona, organiza y produce información de interés y de actualidad basada en la construcción de agenda informativa.

\section{Tipología de géneros radiofónicos}

Caracol Radio mantiene la tradición anglosajona de las noticias desglosadas entre el relato de hechos y la valoración de los mismos; se resalta su información, su sitio cuenta con el espacios titulados: 'Sonó en Caracol 
radio' (resumen de las cinco noticias y voces más importantes del día) y 'Últimos videos' (imágenes de la información más destacada). Esta emisión noticiosa también se trasmite en su canal de YouTube.

La W Radio, desarrolla la entrevista en directo desde la cabina de transmisión vía telefónica, se distingue por su contenido, amplitud y actualidad, a pesar de ello, entra en el sensacionalismo y en la exageración del cubrimiento periodístico. Su página presenta los siguientes espacios: el 'Tema del día' -el usuario participa con su opinión-, 'Regiones' — resumen de las tres noticias del día-, 'Qué cuenta El País' — noticia más importante publicada en este diario Español, el cual pertenece al Grupo Prisa, dueño también de La W Radio —; 'Escuche nuestra señal de audio en vivo —emisión de A.M. y F.M.—, 'Lente W — fotos más destacadas con sus respectivas descripciones - y 'Videos’ —imágenes de las noticias más importantes-.

Blu Radio presenta con mayor énfasis las entrevistas en directo con declaraciones del invitado e intervenciones de los periodistas desde la mesa de trabajo, suelen tener buen ritmo, algunas veces son intensas y tienen algo de dinamismo para que el oyente no se fatigue al escuchar. Se destaca la investigación, documentación y en algunos casos el testimonio de la contraparte; en menor frecuencia desarrollan crónicas. Estos dos géneros los acompañan con comentarios y en algunas ocasiones con la editorial del director. Su página incluye las siguientes secciones: 'Minuto a Minuto' — audio completo de cada noticia—, 'Lo más reciente' — noticias nacionales y regionales - y 'Ver más minuto a minuto' —información de última hora- .

RCN Radio hace énfasis en noticia, su portal tiene las siguientes secciones: 'La radio que se ve' —emisión a través de canales de televisión y telefonía celular-, 'Minuto RCN' — video de la noticia más importante-, 'Últimas noticias' —información actualizada- y 'Escuche lo mejor de Voces RCN' — síntesis de lo destacado del audio de las entrevistas-, 'Sí o No' —opinión del usuario-. Dicha información está respaldada por publicidad y promoción de la emisora.

RCN Radio desarrolla tres tipos de géneros: informativo, opinión y entrevistas. La noticia es el género periodístico por excelencia de esta emisora y de su página web, la cual se presenta de modo completo sobre un hecho actual, pero se descuida la parte humana y la construcción de la realidad social. Se destaca que los periodistas hacen uso de la versatilidad e interpretación de forma minuciosa y verídica del suceso registrado.

En cuanto a la opinión tanto el director como periodistas, presentan su punto de vista sobre el hecho a partir de un contexto basado en el análisis, contrastación y antecedentes; por lo general no necesariamente se adopta una posición bien fundamentada sin formalismos y con buen manejo idiomático. Este género tiene un orden de exposición, la explicación es más coloquial, la estructura del relato es libre y generalmente el periodista asume una posición, pero no se guarda respeto ni decoro por el interlocutor.

La entrevista está basada en proporcionar o recibir información acompañada de una perspectiva interpretativa y valorativa de los hechos noticiosos, se narra algo al propio tiempo que se juzga lo narrado. Se destaca la buena construcción del discurso por parte de cada periodista acorde a las necesidades que los géneros periodísticos — ahora ciberperiodísticos - demandan en su adaptación a la tecnología y a la teoría del hipertexto.

La F.m. maneja la información con poca dinámica, flexible en su contenido y preguntas; hace énfasis en las entrevistas informativas y de opinión; la primera va de la mano con la noticia del día, aporta datos concretos y precisos a través del testimonio de alguien que ha vivido el acontecimiento. La segunda, la de opinión, se centra en preguntas a alguien que conoce a profundidad un tema de interés y que entrega su visión. El director y algunos periodistas deducen consecuencias teóricas sobre los hechos de última hora que por lo general no son contrastados.

Su página incluye secciones "Ver más invitados de la F.m." — testimonios de menor importancia—, 'Ver más editoriales' - posición del medio o invitados sobre el tema del día - y 'Haga su denuncia' — reportería ciudadana- La información está respaldada con publicidad y transmisión en vivo. La F.m. también hace uso de la entrevista y del informe, éste último no lo cubren los otros medios analizados. La constante es la entrevista de análisis a partir de un contexto preciso y en una perspectiva del periodista y del protagonista de la información. Sin embargo, en varias oportunidades se identificó el uso de la entrevista de comentario 
buscando la opinión del que interpreta el relato, pero sin dejar conclusiones. Las cinco emisoras analizadas en promedio desarrollan cuatro géneros periodísticos: la noticia, la entrevista, la crónica y la opinión, como se muestra en la siguiente tabla con sus respectivos porcentajes:

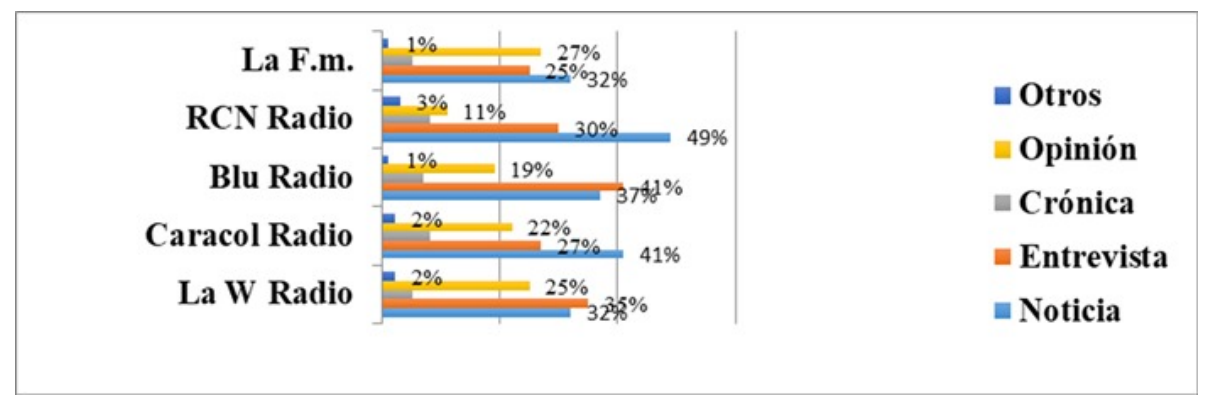

FIGURA 1

Consolidado de géneros empleados en la radio análoga y páginas webs

Fuente: Sitio donde se administra cada página

Los periodistas de La W Radio, afirman que tienen libertad para incluir imágenes como complemento al contenido que se expone en la página tecnológica. Los de Caracol Radio, expresan que no se exige un formato único o clásico de narrativas para presentar la información. Los de Blu Radio, aseguran que la información no está encasillada, sino por el contrario, se permite presentar con la etiqueta de otros formatos, esto no quiere decir, que sean productos de la improvisación. Los periodistas de RCN Radio, utilizan estructuras abiertas de producción con nivel estético, eliminando lo retórico. La F.m. produce diferentes formatos con un lenguaje apropiado en su emisora, y una buena gramática audiovisual en su página web.

\section{Narrativas hibridas e interactivas}

Estas emisoras usan una narrativa libre en sus contenidos mediada por las transformaciones tecnológicas enmarcadas en ecosistemas comunicativos propios, de las audiencias digitales en Colombia. No se evidencia gran diferencia de la emisión análoga a la que se presenta en sus respectivas multi plataformas: móvil, escritorio y audiovisual. La oferta digital de Blue Radio es unificada en cuanto a noticias y deportes, es decir, es igual a las que se presentan en los multicanales del conglomerado del medio al que pertenece: Caracol Televisión, Cromos, El Espectador y Shock.

Estos medios, desarrollan una narrativa transmedia como fórmula de comunicación multimedia e hipertextual, no se basan en la transmisión de un contenido, una historia o pieza periodística a través de diferentes medios como imagen, audio o vídeo, ni se respetan las propias estructuras de expresión de cada uno de ellos. Se identifica la falta de creación de nuevas fórmulas comunicacionales en el entorno digital, de uso de diferentes lenguajes para comunicar de una manera más profunda y completa para cada medio, crossmedia o multiplataforma, aunque en pocas oportunidades la narración contiene mapas, audio, fotografías y un diseño web adaptado al acontecimiento, por lo cual se infiere que el periodista no usa el mejor esquema narrativo para cada parte de su información y de su investigación.

A pesar que estas cadenas quieren reflejar en la red un proceso multimedial, no lo consiguen puesto que lo que presentan es una combinación de lenguajes similares a los impresos y audiovisuales, tampoco existe diferencia entre narrativas de sus contenidos en AM y FM y su migración a lo digital. Caracol Radio y RCN Radio ofrecen propuestas informativas breves y ágiles en promedio de dos a tres minutos sin perder la profundidad y agilidad. La W Radio en su contenido mantiene la esencia de lo convencional, en algunas ocasiones apuesta por nuevos formatos y narrativas interactivas. No existe en La F.m. un valor añadido al flujo de información ni organización narrativa, contexto, sumario, datos y descripción. 


\section{Audiencias análogas y digitales}

La W Radio y Caracol Radio, enfocan su audiencia tanto en lo análogo como en lo digital a partir de estrategias de contenido y coyunturas especiales de información, mientras que Blu Radio, RCN Radio y La F.m. buscan un liderazgo digital y una sinergia al grupo de medios al cual pertenece. Estas cinco emisoras sustentan su crecimiento de audiencias en una apuesta decidida en el desarrollo de temas de agenda propia, uso de nuevas formas para narrar historias, producción y presentación de contenidos periodísticos centrados en información, investigaciones y opinión a tono en las necesidades de los nuevos consumidores.

Las constantes de estos medios en su página tecnológica, consiste en que la audiencia se centra en dos clases: primera, el nuevo lector capaz de marcar la agenda, de anunciar en Facebook sus angustias informativas en busca de apoyo o de twittear sobre la noticia. El periodista está atento a estas inquietudes para tomar la determinación de tenerlas en cuenta o ignorarlas. La segunda clase, es la audición de los diferentes podcasts que presenta cada medio en su respectiva página.

Las cinco emisoras segmentan sus públicos, se diferencia cada una de ellas en el tipo y la composición de sus oyentes por edades, sexos y nivel socioeconómico. La W Radio, Blu Radio y La F.m., cubren el 61\% de su audiencia menor a 45 años en estratos 4, 5 y 6, mientras que Caracol Radio y RCN Radio tienen escuchas de 35 años en adelante de estratos medios y altos, con el 49\% de sintonía. En este sentido, el consumo de información es del 82\% principalmente de 5:30 a.m. a 9:00 a.m.; sus usuarios en la red son más lectores de información, que escuchas.

Caracol Radio y RCN Radio han implementado tecnología de última generación en cabinas de radio como cámaras webs y actividades para incentivar la participación de la audiencia como trinos en vivo. La F.m. abre un buzón donde deja programas cortos, imágenes y mensajes para conocer las opiniones de los escuchas y así medir las preferencias de su grupo objetivo.

Estas radios crean nodos de información a través de redes sociales como Facebook, la cual se ubica como primera con 31,5\% del total de su audiencia; en segundo puesto está Twitter con 16,5\%, y en tercero Instagram con $12 \%$. El 30,9 \% de los usuarios de La W Radio, Caracol Radio y Blu Radio abren en primer lugar Facebook tan pronto tienen acceso a Internet para enterarse de las últimas informaciones, mientras que los usuarios de RCN Radio y La F.m lo hacen mediante Twitter, con el 20,1\%, y WhatsApp con el 19,4\%.

\section{Rutinas periodísticas}

Estas emisoras cuentan con periodistas para sus emisiones en AM y FM mientras que sus páginas web están manejadas por equipos de tres a siete personas distribuidas por lo general en un programador que crea motores de búsqueda, un diseñador del sitio coherente con la línea de información de los respectivos medios del conglomerado, un administrador de contenidos quien maneja la arquitectura de la información y la transfiere de lo análogo a digital.

El 88\% de los periodistas que se desempeñan en estas emisoras y sus correspondientes portales, dominan los procesos de producción, grabación, edición, emisión de información y parrilla de programación que ofrece cada medio. El 58\% es hábil en la creación de contenidos e historias y en producción análoga y en línea. El $72 \%$, no posee competencias en Excel, manejo de equipos de radiodifusión, uso de sistemas de administración de contenido (CMS), multimedia y usabilidad.

El 51\% de los periodistas tiene vinculación laboral mediante contrato a término indefinido, a pesar de que más del $84 \%$ cuenta con un título profesional y el 16\% son empíricos. Los demás, trabajan en condiciones de informalidad: un $21 \%$ está vinculado a sus respectivos medios de comunicación mediante contrato a término definido de un año, $12 \%$ por prestación de servicios y el 16\% restante, percibe sus ingresos con venta de cupos publicitarios. 
El $81 \%$ domina las herramientas informáticas y el software de edición de audio, el $82 \%$ no maneja el lenguaje de Internet ni la navegación en la web. Los decanos de las facultades de Comunicación y Periodismo y los directores de estos programas, afirman que dicho profesional debería contar con competencias en comunicación digital para lograr la participación efectiva con las diferentes audiencias; mantener el respeto, la honestidad y la responsabilidad con un gran sentido de liderazgo y humanismo; poseer habilidades para conformar equipos de trabajo y manejo de la expresión, lectura, redacción y comprensión de la realidad del país y del mundo.

\section{Análisis y discusión}

La radio comercial en Colombia, se sostiene en conglomerados entramados con otros medios de comunicación creando sinergia grupal o alianzas estratégicas en un contexto multimediático, con compañías extranjeras. Hoy, es una radio moderna, rica en tecnología, con enlaces informativos con otras estaciones del exterior, con redes de información instantánea y corresponsales en todo el país y en las principales ciudades del mundo.

La participación de la audiencia, no forma parte de la estrategia de difusión de la información ni son tenidos en cuenta sus comentarios; por tanto, se realiza un periodismo multimedia, pero sin nuevas vías de difusión y de conexión con los oyentes, lo único que se hace es que el usuario profundice la información a través de hipervínculos que lo llevan a otras narraciones, datos, noticias y temas relacionados. En sus páginas de Internet no hay un espacio destinado para los comentarios de los usuarios; en otras palabras, presentan un soporte mutuo en el que el discurso multimedia y transmediático, se apoya en interacciones narrativas de las audiencias.

Por estas razones, los directores están atentos a las evaluaciones de los consumidores sobre cada plataforma, página y contenidos, mientras que en la radio análoga tan solo esperan los comentarios esporádicos de los oyentes. Los usuarios participan más en los medios digitales, que en los tradicionales. La explicación para el aumento en el número de visitantes de estas páginas digitales, se encuentra en la presentación de información en formatos audiovisuales y la cobertura de los hechos noticiosos más importantes, con el rigor y la calidad que ha caracterizado a cada medio de comunicación.

También, ha jugado un papel importante la capacidad para proponer agenda propia sobre temas de interés para la audiencia, a través de varias estrategias, una de ellas, son las redes sociales donde más se genera interacción y producción de contenidos por parte de los usuarios. Estas son dinámicas, pero distan de la gran sintonía que tienen en sus bandas de A.M. y F.M. Utilizan Fecebooky Twiter para informar sobre las novedades en la parrilla de programación, los avisos de los contenidos, e incluso, publican cada sección para animar a sus escuchas a que opinen y participen por medio de comentarios. Su objetivo es lograr un intercambio de información y mensajes entre el oyente y la emisora.

Estas emisoras intentan buscar oyentes sin saber con precisión qué ofrecen, por eso se encargan de poner en su parrilla de programación 'de todo un poco'. El modelo más recurrente es en la promoción cruzada del contenido informativo o la cobertura multimedia de noticias o eventos puntuales, pero estos no son adaptados a los nuevos formatos para móviles y tabletas. De este modo, el periodista se considera un proveedor de contenidos, haciendo hincapié en la diversidad de soportes en los que puede difundirlos.

Así mismo, existe una pérdida de calidad de los contenidos que se presentan, pues los periodistas están supeditados a la inmediatez y alerta del tiempo de permanencia del usuario en cada información, lo cual condiciona que la noticia no tenga más de dos a tres minutos o en su defecto de cuatro párrafos para su página tecnológica. Predomina la reiteración de fórmulas, la presentación de información conocida, la saturación y repetición de noticias. 
Presentan titulares breves y de interés muy cercanos a su audiencia, a los dispositivos móviles y redes sociales. Agregan información de otros medios clásicos o digitales, le imprimen su sello particular para cubrir, desarrollar e informar el acontecimiento que por lo general, lo hacen en vivo desde el lugar noticioso, son sus únicos diferenciales aunque el ecosistema mediático se mantiene, no se experimenta una nueva cultura digital.

Estos portales de dichas emisoras producen contenidos que integran varios elementos comunicativos, los cuales permiten al público acceder a la información de múltiples formas, con lo que se relaciona la llamada Era de la Información, conocida por revolucionar la manera tradicional de comunicar y relacionarse con el otro, ya que rompe límites de espacio y tiempo entre el emisor y el receptor. No incluyen otros géneros ni hay una evolución de la narrativa radiofónica, se informa desde un solo formato y se desconocen distintos modos de contar.

La combinación perfecta de contenidos, requiere un balance entre la calidad informativa que incluye el tiempo dedicado a la investigación de cada noticia, la manera en la que se transmite al público y su pertinencia y relevancia en relación con la audiencia a la que se informa. Un programa radial, resulta exitoso cuando la estética no supera el trabajo periodístico y cuando este no predomina en la transmisión, se vuelve aburrido, acartonado, fragmentado y difícil de digerir.

Los contenidos presentados en las páginas de estas emisoras son visibles, sencillos y localizables en motores de búsqueda por parte del usuario. Se resalta el anclaje de los temas de interés por los hipervínculos ubicados sobre imágenes, audios y textos que conducen a ampliar el tema. Estas páginas poseen su respectiva Pagerank, la cual está en una escala de 6 a 8 sobre el rango de 10, medida que da Google para destacar el sitio y determinar el número de enlaces a la página que le dan sus lectores.

Estas estaciones radiales emiten sus mismos informativos tanto en AM y FM como en sus páginas digitales en las que se combinan noticias generales, política, judicial, economía y deporte, apoyadas por textos, fotografías, ilustraciones, locuciones y en algunos casos por vídeos. La W Radio y Caracol Radio, disponen de herramientas para mejorar la organización de la información en cada plataforma y emplean identificadores para que su contenido sea localizado con rapidez.

Las preferencias de contenidos temáticos de periodistas y consumidores tanto de las emisoras dominantes como de sus sitios web presentan una marcada divergencia, los primeros con un sentido sensacionalista, ideológico y regionalista; y los segundos, con exigencia de nuevos formatos basados en la neutralidad y profundidad en el cubrimiento informativo.

Más allá de canales, soporte y de las convergencias que logran dichas radios, usan diversas intertextualidades e interacciones comunicativas como hipertextos, formatos, estilos lingüísticos y expresivos de manera más asertiva, con el fin de aumentar la audiencia que cada vez es más migrante, plural, activa y buscadora de pantallas en este nuevo escenario digital. Estos medios no sustituyen unas pantallas por otras, sino más bien hacen reacomodos tanto de las ofertas programáticas, como del tipo de interacciones narrativas de las audiencias.

Las emisoras analizadas ven como alternativa de programación la descarga por demanda de su contenido por parte del usuario desde un celular, computador o tableta, lo cual ha implicado un cambio importante en la manera como se consume radio. Anteriormente un periodista tradicional debía pensar en lo que le gustaba a la mayoría de la audiencia para ser comercialmente viable, y esperar a escuchar el programa a una hora determinada en el respectivo dial, hoy en día, lo puede hacer a la hora que desee. Por eso, estas emisoras ofrecen podcasts con contenido similar a sus diferentes oyentes, carecen de datos y contexto, los presentan en sus respectivas páginas, pero no en otras plataformas como iTunes, SoundCloud o YouTube.

Se han limitado a realizar una adaptación de los géneros informativos, sin considerar las propiedades de la comunicación oral, existe fugacidad del mensaje y la presencia de elementos no lingüísticos con rasgos que rompen con la estructura y producción formal de los contenidos periodísticos. Usan géneros como: noticia, entrevista y crónica. Las notas más vistas en cada sitio web, muestran que las preferencias temáticas de los consumidores, difieren a la de los periodistas. 
La crónica se presenta esporádicamente en las diferentes emisiones análogas y en los podcasts de la página digital, los periodistas consultados afirman que este género exige mayor capacidad de investigación para buscar antecedentes y consecuencias de lo sucedido, mayores cualidades analíticas y una técnica descriptiva y narrativa más perfeccionada, las cuales no se presentan con regularidad. La información de actualidad se cumple a medias, no se profundiza ni se relaciona con su contexto; se abusa de la interpretación y de los comentarios, el periodista toma partido por una postura u otra a partir de la información que presenta y trata de convencer al usuario de que su posición sobre el tema, es la correcta.

El lenguaje utilizado en la crónica es muy similar: exceso de adjetivos que le resta claridad y objetividad al mensaje; uso de palabras, ironías y oraciones sin sentido; falta de fluidez en la conversación y expresiones ofensivas principalmente en el desarrollo de la entrevista, en algunos con tono agresivo, con comentarios incoherentes y sin contexto. Se presentan las mismas noticias y entrevistas en tanto en la plataforma análoga como en su página digital, ya sea por contagio o por sensacionalismo, lo cual les da a estas radios, según los periodistas entrevistados, mayor audiencia y ganancia.

Por estas razones, desarrollan una narrativa transmedia a través una fórmula de comunicación e hipertextualidad, basada en la transmisión de la información periodística acompañada de imagen, audio y vídeo, pero no usan narrativas multimedial para cada contenido. Sus sitios digitales, combinan diferentes medios de expresión como banda sonora, diálogos, sonido ambiente, fotografía, vídeo y textos.

Se resalta la actualización de sus páginas, en promedio lo hacen cada dos horas. La W Radio y Caracol Radio amplían la información en sus respectivas emisoras en el momento que se produce la noticia, pero no lo hacen en tiempo real para sus páginas. Dichos sitios son estáticos, con poca interactividad; les falta precisión en algunas informaciones; la entrevista a testigos constituye una presión indebida y se sobredimensionan los conflictos; hay indiferencia por los hechos positivos, se privilegia el terror y la muerte como el principal escenario noticioso.

Estas emisoras ven una alternativa en sus páginas digitales, la distribución y consumo de podcasts; aunque RCN y La F.m. presentan dificultades tecnológicas para la descarga de algunos contenidos y carecen de información atractiva para sus usuarios. Además, tienen problemas para la medición y caracterización de audiencias y falta de promoción publicitaria de su información, por lo cual se infiere que la producción, distribución y recepción no están tan desarrolladas en estas páginas. Con el tiempo van agotando sus posibilidades de identificar un nicho de mercado, aquellos interesados en streaming, en podcast o en redes sociales.

Cada estación radial tiene su sitio digital, con links que redirigen a otras páginas que pertenecen al mismo grupo mediático. Su web es sobria, simple y con suficiente contenido, la presentación de su página da una imagen anticuada de la emisora por su maquetación y por su aspecto desfasado. Por lo general, presentan una opción de 'Audio en vivo' que permite acceder mediante streaming a la emisión en directo, es decir, un enlace que se redirecciona a un centro de emisiones en línea de cada grupo que posibilita el acceso al audio en directo.

La web de cada radio no tiene una parrilla de programación ni una descripción de los programas, mucho menos una biografía de los periodistas. A diario se cuelga en la red un 'sondeo de opinión' para que los internautas y oyentes voten acerca de algún asunto noticioso. Cada una de las emisoras relaciona en promedio un listado de seis audios más destacados de cada jornada.

Debido a lo anterior, se alteran las rutinas del profesional de la comunicación y del periodismo, se convierte una vez más en el mediador entre las TIC y el usuario, con potencial y capacidad de trabajar simultáneamente en ambientes análogos y digitales, tiene un sentido claro de la interactividad y de altos índices de audiencias. Dichas competencias las complementa con habilidades comunicativas y argumentativas; inclusive es gestor y recuperador de contenidos; se desempeña como Community Manager o Social Media Manager. Conoce del entorno digital en su conjunto: audiencias, fuentes y anunciantes. 


\section{Conclusiones}

Estas estaciones radiales se están convirtiendo en grupos multimedia, con presencia en diversos mercados de la comunicación, le dan prelación a los medios digitales informativos con orientación al cubrimiento nacional más que al internacional, incluso este último es superado por el interés regional o departamental.

Esta información endogámica tiene mayor visibilidad en A.M. y F.M. que en la página web. La consigna es ponerle el sello a sus respectivas características periodísticas, para cada ecosistema mediático de acuerdo con los nichos de mercado y estratificación de audiencia. A pesar de lo anterior, no se presenta información especializada para las diferentes plataformas, algunos medios proponen agendas noticiosas generalizadas.

El contenido de estos medios informativos no son profundos y sus temas son recurrentes, lo que crea una espiral del silencio, pues repiten información que ya ha sido transmitida horas antes. Su objetivo principal es el de entretener y no el de informar. Se necesita de una radio con un discurso alternativo, diferente al ofrecido por los medios dominantes, de características propias, significativas, que busque la propia originalidad e innovación, continuidad y creatividad, orientación democrática y participativa.

La información es adecuada para lo análogo, mas no para lo digital, la inmediatez, la interactividad, la democratización de la información, lo mismo que sus lenguajes y formas son tan solo un deseo de estos medios; en otras palabras, se necesita de una imprescindible reformulación. Una radio con la participación del actor con el medio, es decir, opuesta a los esquemas dominantes, que sea plural, incluyente, abierta, democrática y multidireccional.

Las emisoras tradicionales que migraron a Internet permiten un mayor grado de interactividad, al tiempo que ofrecen nuevos sistemas de comunicación entre la radio y el oyente; no es un altavoz digital de la radio convencional. Sin duda, ha sido la radio en la web la que mejor se ha desarrollado, constituyéndose así en la muestra más evidente de lo que nos podría deparar la radio del futuro.

Es por lo anterior, que los contenidos deberán estar en coherencia con los canales, formatos y la línea editorial de cada emisora, para lograr una óptima transmisión, atendiendo el valor del mensaje, la contextualización y el desarrollo de una información veraz, ágil y oportuna, con manejo ético y conocimiento del potencial informativo como multiplicador de criterios que generan opinión pública.

Estos nuevos formatos, invitan a que el medio y aquellos que están inmersos en este, introduzcan cambios, lo cual obliga a plantear estrategias y alternativas para no perder audiencia lo que redundaría en beneficio de ellas que están buscando lo mejor. La calidad nunca va a reñir con la audiencia ni con la sintonía. Y eso se traduce en equipos de trabajo que día a día se consolidan con expertos en diferentes campos y plataformas, principalmente de Internet.

Es así que la radio comercial está segmentada y ha logrado captar usuarios para una gran variedad de programas en franjas específicas. Las audiencias en los medios digitales tienen mayor participación, establecen otro tipo de relación con periodistas primordialmente a través de las redes sociales. Las emisoras analizadas presentan entornos digitales propicios más para jóvenes que para adultos, generan procesos de comunicación de doble vía; a pesar de ello, estos usuarios no son creadores de contenidos o prosumidores.

Es por esto, que estas radios se preocupan por su entorno digital, por una comunicación efectiva con su audiencia, por la interacción persona-persona por persona-ordenador y por consumidores que se sientan identificados con los contenidos. A pesar de lo dicho, cada entorno digital mediático no es efectivo, atractivo, útil y convergente, no logra en varias ocasiones articular en un solo espacio la fotografía, el video, el texto, la infografía y el audio. Esta falta de hipermediaciones, se debe a que no se tienen identificados claramente los nichos de mercado ni la duplicación de audiencias para radio análoga y sus sitios web.

El periodista que labora en estas radios, desarrolla las competencias personales: flexibilidad, adaptabilidad, creatividad y versatilidad; profesionales: formación académica y conocimiento de lenguajes múltiples; y técnicas: manejo y gestión de fuentes y edición perfecta de contenido. Además, hace uso adecuado de la 
polivalencia mediática: informa sobre un mismo tema para distintos medios o formatos de una misma organización.

Es claro que estamos asistiendo a uno de los cambios tecnológicos más sustanciales en materia de telecomunicaciones y radiodifusión en casi un siglo, la digitalización, pero de momento, y especialmente en el ámbito radiofónico, existe bastante confusión, muchos lugares comunes y una radio digital cuyo futuro sigue todavía bastante desdibujado para estas emisoras analizadas.

A pesar de ello, la radio seguirá presente en la vida cotidiana de los colombianos y seguramente encontrará la forma de acomodarse a los avances tecnológicos de la actualidad. Por medio del clásico radio de pilas, de una aplicación celular o de una página web, la radio se reinventa y se consolida como uno de los principales medios de comunicación de Colombia.

Por consiguiente, surgen algunas preguntas de investigación: ¿Qué estrategias se podrían implementar para reducir la brecha entre la oferta de interés periodístico y la demanda de las noticias en línea que sus audiencias consideren atractivo? ¿Qué retos y oportunidades para las emisoras análogas se avecinan para competir en el mundo digital? ¿Qué giros y rupturas conceptuales sufrirá el campo de la comunicación en esta transformación de los medios radiales?

\section{Agradecimientos}

Este artículo es producto del proyecto de investigación titulado Convergencia mediática, nuevos perfiles del comunicador y periodista. Referencia IN.BG.094.16.003, financiado por la escuela de Ciencias de la Comunicación Social y Periodismo, de la Universidad Sergio Arboleda.

\section{Bibliografía}

Asociación Colombiana de Investigación de Medios[ACIM] (2017). Base de Datos del EGM Ola 1-2017. [en línea ], Recuperado julio 7, 2017 de http://www.acimcolombia.com/fechas/entrega-base-ola-1-2017/

Asociación Colombiana de Investigación de Medios [ACIM] (2017, Febrero 16). Comisión Nacional de Televisión. CNTV - Oficina de Planeación. .

Alfaro, R. (1993). Una comunicación para otro desarrollo. Lima: Calandria.

Arnheim, R. (2015). Estética radiofónica. Barcelona, España: GG MassMedia.

Balsebre, A. (1994). El lenguaje radiofónico. Madrid: Editorial Cátedra.

Blu Radio (s.f.) Recuperado de http://www.bluradio.com

Bonet. M. (2017). La radio riberdigital, estándares tecnológicos y plataformas de distribución. Portal de la Comunicación InCom-UAB: El portal de los estudios de comunicación, Institut de la Comunicació (InComUAB). [en línea], Recuperado agosto 17, 2017 de http://www.portalcomunicacion.com/uploads/pdf/29_esp. pdf

Caracol Radio (s.f.) Recuperado de http://www.caracol.com.co

Delgado, C., \& Rioboo, J. (2005). Libros de la Onda. En actas del 24 congreso del IBBY, Sevilla, España.

Documento de política sectorial del Ministerio de Comunicaciones. (2004). Políticas para la Radiodifusión en Colombia. Bogotá-Colombia.

Dominique, W. (2010). Informar no es comunicar: contra la ideología tecnológica. [en línea], Recuperado junio 18, 2017 de https://www.casadellibro.com/libro-informar-no-es-comunicar-contra-la.../1694087

Duhe, S., Mortimer, M., \& Chow, S. (2004). Convergence in North American TV Newsrooms: A Nationwide Look. Convergence, 10(2), 81-104. https://doi.org/10.1177/135485650401000206

Estudio Continuo de Audiencia Radial- [ECAR]. (2017a). Resultado de encuesta de radio. [en línea], disponible en: http://www.encuestascnc.com/cnc_ecar/, recuperado: 10 de juliode 2017. 
Estudio Continuo de Audiencia Radial [ECAR]. (2017b). Sintonía y contenidos. [en línea], disponible en: https://ju anpalaguna.wordpress.com/ecar-estudio-continuo-de-audiencia-radial/, recuperado: 17 de agosto de 2017.

Estudio general de medios [EGM] (2017). Boletines informativos. [en línea], disponible en: en http://www.acimcol ombia.com/boletines/boletines/ Recuperado 25 de marzo de 2018

Forgacs, D. (2001). Scenarios for the digital age: Convergence, personalization, exclusion. Modern Italy, 6(2), 129-139. https://doi.org/10.1017/S1353294400011935

García Avilés, J., \& Carvajal, M. (2008), “Integrated and Cross-Media Newsroom convergence: two models of multimedia news production: The Cases of Novotécnica and La Verdad Multimediain Spain". Convergence, 14(2), 223-241. https://doi.org/10.1177/1354856507087945

Gordon, R. (2003). The Meanings and Implications of Convergence. En: Kawamoto, K. (ed.). Digital Journalism: Emerging Media and the ChangingHorizons of Journalism (pp 111-113). Lanham, Md.: Rowman \& Littlefield Publishers.

Gutiérrez, C. (2013). Calidad informativa en la era digital: el gran reto. Palabra Clave, 16(3), 666-670. Recuperado de http://palabraclave.unisabana.edu.co/index.php/palabraclave/article/view/3610/3312

Gutiérrez, G., Ribes, X., \& Monclús, B. (2012). La audiencia juvenil y el acceso a la radio musical de antena convencional a través de internet. Revista Comunicación y Sociedad. 24(2), 305-331.

Idei, N. (2004). What happened to convergence? En: RICE, J.; Mckerman, B. (Eds). Creating digital content (pp 97-98). New York: McGraw-Hill, XIX-XXII.

Jenkins, H. (2004). The Cultural Logic of Media Convergence. International Journal of Cultural Studies, 7(1), 33-43. https://doi.org/10.1177/1367877904040603

Kaplún, M. (1994). Producción de Programas de Radio: el guión - la realización. México: Editorial Cromocolor.

Killebrew, K. (2005). Culture, Creativityand Convergence: Managing Journalists in a Changing Information Workplace. The International Journal on Media Management (2003), 5(1), 39-46. https://doi.org/10.1080/14 241270309390017

Klinenberg, E. (2005). Convergence: News Production in a Digital Age. The Annals of the American Academy of Political and Social Science, 597(1), 48-64. https://doi.org/10.1177/0002716204270346

La fm (s.f.) Recuperado de http://www.lafm.com.co

Lavers, D. (2017, December). DAB - If you don't go digital, you'll die'. Broadcast Dialogue Magazine .

Lawson-Borders, G. (2006). Media Organizationsand Convergence. Case Studies of Media Convergence Pioneers. New Jersey: Lawrence Erlbaum.

Martínez, M., \& Herrera, S. (2004). Los géneros radiofónicos en la teoría de la redacción periodística en España Luces y sombras de los estudios realizados hasta la actualidad. Revista Comunicación y Sociedad, XVII(1), 115-143. Recuperado de https://www.researchgate.net/publication/50517244_Los_generos_radiofonicos_en_la_teoria_de_la_reda ccion_periodistica_en_Espana_Luces_y_sombras_de_los_estudios_realizados_hasta_la_actualidad

Mata, M. (1993). Lo que dicen las radios. Quito: ALER.

Meridian Group. (2017). Móviles y web. [en línea], Recuperado de http://www.meridiangroupsa.com/es/, recuperado: 18 de junio de 2017.

Montse, B. (2011). La radio digital, estándares tecnológicos y plataformas de distribución. Portal de la Comunicación InCom-UAB. Lecciones del Portal. 6. [en línea], Recuperado mayo 15, 2017 de http://ow.ly/qHbTH.

Ministerio de Tecnologías de la Información y las Comunicaciones- [Min TIC]. (2017). Registro TIC de Radiodifusión Sonora. [en línea ], Recuperado 8 de marzo de http://www.mintic.gov.co/portal/604/w3-prop ertyvalue-6159.html

Peñafiel, C., \& López, N. (2002). Claves para la era digital: Evolución hacia nuevos medios, nuevos lenguajes y nuevos servicios. Bilbao: Servicio Editorial de la universidad del País Vasco.

Romero, H. (2013). Acercándonos a la radio digital terrestre desde la radio en la Red. Chasqui (123), 34-39. https:/ /doi.org/10.16921/chasqui.v0i123.52 
Salaverría, R. y García, J. (2008). La convergencia tecnológica en los medios de comunicación: retos para el periodismo. RevistaTripodos, (23), 31-47.

Sierra, J. (2010). Estudio de la oferta de programación de las radios autonómicas en España. Revista Latina de comunicación social, (65). https://doi.org/10.4185/RLCS-65-2010-906-368-378

Theodoropoulou, V. (2003). Consumer Convergence. Digital Television and the Early Interactive Audience in the UK. En: Ferrel Lowe, G.; Hujanen, T. (eds.) Broadcasting and Convergence. New Articulations of the Public Service Remit (pp 285-297). Gotemburgo: Nordicom.

Valencia, J. (2008). La radio digital: ¿Una demanda social o un nuevo escenario de las pugnas del capitalismo globalizado? Revista Signo y Pensamiento, 27(52), 110 - 118. Recuperado de http://revistas.javeriana.edu.co/in dex.php/signoypensamiento/article/view/3719

W Radio (s.f.) Recuperado de http://www.wradio.com.co

\section{Notas}

1 Según las tendencias de consumo sobre información de los principales medios en Internet en Colombia realizado por Meridian Group (2017), frente a prensa y televisión, la radio provoca un 18\% de actividad en Internet de la cual las menciones en redes corresponde al 31\% los retweets al 34\% y las interacciones con el medio el 35\%. Este estudio que tuvo en cuenta las emisoras de radio Caracol Radio, La Fm. y la W Radio, determinó características del consumo de contenidos, por ejemplo revela que de todos los usuarios interactúan con medios radiales en Twitter el $68 \%$ corresponde al sexo masculino, el $26 \%$ al femenino y el $6 \%$ a cuentas institucionales.

* Artículo de investigación científico.

\section{Licencia Creative Commons CC BY 4.0}

Cómo citar el artículo: Zambrano Ayala, W. (2018). La radio comercial en Colombia: El nuevo panorama digital de la comunicación y del periodismo. Signo y Pensamiento, 37(72), 106-126. https://doi.org/10.111 44/Javeriana.syp37-72.rccn 